\title{
Coronary collaterals and risk for restenosis after percutaneous coronary interventions: a meta- analysis
}

\author{
Pascal Meier ${ }^{1 * \dagger}$, Andreas Indermuehle ${ }^{2 \dagger}$, Bertram Pitt ${ }^{3}$, Tobias Traupe ${ }^{4}$, Stefano F de Marchi ${ }^{5}$, Tom Crake ${ }^{1}$,
} Guido Knapp ${ }^{6}$, Alexandra J Lansky ${ }^{7}$ and Christian Seiler ${ }^{4}$

\begin{abstract}
Background: The benefit of the coronary collateral circulation (natural bypass network) on survival is well established. However, data derived from smaller studies indicates that coronary collaterals may increase the risk for restenosis after percutaneous coronary interventions. The purpose of this systematic review and meta-analysis of observational studies was to explore the impact of the collateral circulation on the risk for restenosis.

Methods: We searched the MEDLINE, EMBASE and ISI Web of Science databases (2001 to 15 July 2011). Random effects models were used to calculate summary risk ratios (RR) for restenosis. The primary endpoint was angiographic restenosis $>50 \%$.

Results: A total of 7 studies enrolling 1,425 subjects were integrated in this analysis. On average across studies, the presence of a good collateralization was predictive for restenosis (risk ratio (RR) 1.40 ( $95 \% \mathrm{Cl} 1.09$ to 1.80); $P=$ 0.009). This risk ratio was consistent in the subgroup analyses where collateralization was assessed with intracoronary pressure measurements (RR 1.37 (95\% Cl 1.03 to 1.83); $P=0.038$ ) versus visual assessment (RR 1.41 ( $95 \% \mathrm{Cl} 1.00$ to 1.99); $P=0.049$ ). For the subgroup of patients with stable coronary artery disease (CAD), the RR for restenosis with 'good collaterals' was 1.64 ( $95 \% \mathrm{Cl} 1.14$ to 2.35$)$ compared to 'poor collaterals' $(P=0.008)$. For patients with acute myocardial infarction, however, the RR for restenosis with 'good collateralization' was only 1.23 (95\% Cl 0.89 to 1.69$) ; P=0.212$.

Conclusions: The risk of restenosis after percutaneous coronary intervention $(\mathrm{PCl})$ is increased in patients with good coronary collateralization. Assessment of the coronary collateral circulation before PCI may be useful for risk stratification and for the choice of antiproliferative measures (drug-eluting stent instead bare-metal stent, cilostazol).
\end{abstract}

Keywords: coronary collateral circulation, meta-analysis, restenosis, therapy failure

\section{Background}

Coronary collaterals are present in normal and diseased hearts. This coronary collateral circulation (CCC) has the potential to alleviate myocardial ischemia $[1,2]$. There is strong evidence that the CCC has a positive impact on survival $[3,4]$. However, some data suggested an increased risk for restenosis following percutaneous coronary intervention (PCI) in patients with good

\footnotetext{
* Correspondence: pascalmeier74@gmail.com

+ Contributed equally

${ }^{1}$ The Heart Hospital London, University College London Hospital Trust, London, UK

Full list of author information is available at the end of the article
}

collateralization; however, the findings derive from small studies and have been rather inconsistent $[5,6]$. The purpose of this systematic review and meta-analysis was to integrate all available data in order to provide a clearer understanding of the impact of the coronary collateral on the risk for restenosis following PCI.

\section{Methods}

The study was performed according to the Meta-analysis Of Observational Studies in Epidemiology (MOOSE) guidelines for meta-analyses of observational data (Additional file 1) [7]. Planning and study design was performed by two authors (CS, PM) including creation of an

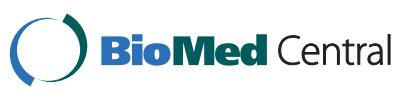


electronic database with variables of interest (Microsoft Excel; Microsoft, Redmond, WA, USA). Primary and secondary endpoints, variables of interest and search strategy (databases, sources for unpublished data) were defined in a strategy outline that can be obtained from the study authors on request.

\section{Search strategy}

We searched the EMBASE, PubMed, MEDLINE, BIOS, International Pharmaceutical Abstracts database, and ISI Web of Science databases from 1980 to 15 July 2011. In addition, abstract lists and conference proceedings from the 2006 to 2010 scientific meetings of the American College of Cardiology, the European Society of Cardiology, the symposium on Transcatheter Cardiovascular Therapeutics, the American Heart Association, and the World Congress of Cardiology were searched. We also considered published review articles, editorials, and internet-based sources of information http://www.tctmd.com, http://www.theheart.org, http://www.europcronline.com, http://www.cardiosource.com, and http://www.crtonline. com to assess potential information on studies of interest. Reference lists of selected articles were reviewed for other potentially relevant citations. No language restriction was applied. Authors of selected studies were contacted to obtain further information if needed. All prospective studies reporting on an association between restenosis probability and coronary collateral circulation were included in this analysis. Retrospective case-control studies were not considered. We focused on prospective cohort studies because our objective was to define the value of collaterals as a marker for future restenosis. Furthermore, we excluded retrospective case-control studies because we think that matching of cases with controls could introduce critical bias; and in many cases, collaterals cannot be assessed accurately in retrospect.

The detailed search syntax used for the Medline database is shown in Additional file 2. The syntax for other databases was similar, but was adapted where necessary.

\section{Study selection}

In a two-step selection process, the titles and abstracts of all citations were reviewed by two researchers (PM, $\mathrm{CS})$ to identify potentially relevant studies. In a second step, the full text of corresponding publications was reviewed to assess whether the studies met the following inclusion criteria: association of restenosis risk and the degree of coronary collateralization (Figure 1).

\section{Data extraction and quality assessment}

Relevant information from the articles including baseline clinical characteristics of the study population and outcome measures was extracted using the prepared standardized extraction database (Excel). The quality of each study was assessed with the Newcastle-Ottawa Scale (NOS) for assessing the quality of non-randomized studies in meta-analyses (Table 1) [8]. Based on this scale, an additional sensitivity analysis of studies with superior quality was performed (at least seven of eight points). We did not use the quality scores for study weighting due to the limitations inherent to such an approach [9].

\section{Endpoints}

The primary endpoint of this analysis was angiographic binary restenosis (> 50\% restenosis). This dichotomized endpoint definition was selected because we expected that most studies report on dichotomized values; classically, a $50 \%$ cut off has been used in angioplasty studies. This value was mainly based on the experimental work of Gould et al., demonstrating blunting of the hyperemic response at a stenosis degree of 50\% [10].

\section{Definitions}

Good collateralization was defined differently for the individual studies. Three studies performed a visual assessment (Rentrop score) [11] and used a score of $\leq 1$ for poor collateralization (no or only faintly visible collaterals). In brief, the Rentrop score assigns four degrees of collateralization depending on the presence and extension of the collateral filling of coronary epicardial vessels during a coronary angiogram (grade $0=$ no collaterals; grade 1 = side branch filling of the recipient artery without filling of the main epicardial artery; grade $2=$ partial filling of the main epicardial recipient artery; grade $3=$ complete filling of the main epicardial recipient artery). Four studies based their collateral quantification on intracoronary pressure measurements (collateral flow index (CFI)) [12] (Table 2) and defined poor collateralization as a CFI $<0.25$. The CFI defines the proportion of blood flow that derives from the collateral circulation in comparison to the antegrade blood flow through the main coronary artery. The CFI is measured with a pressure sensor tipped coronary guidewire, which is placed in the distal vessel. The collateral flow index calculation is based on the occlusion pressure during a 1-minute balloon inflation and the pressure proximal to the balloon occlusion (aortic pressure). The central venous pressure is subtracted from these two pressures to correct for the back pressure: $\mathrm{CFI}=$ (occlusion pressure - central venous pressure $) \div$ (systemic pressure - central venous pressure).

\section{Data synthesis and analysis}

Data from included studies were combined to estimate the pooled impact (risk ratio (RR)) of good collateralization versus poor collateralization. Calculations were based on a DerSirmonian and Laird random-effects model [13]. This model assumes that the true effects vary between studies for unknown reasons. The primary summary measure 


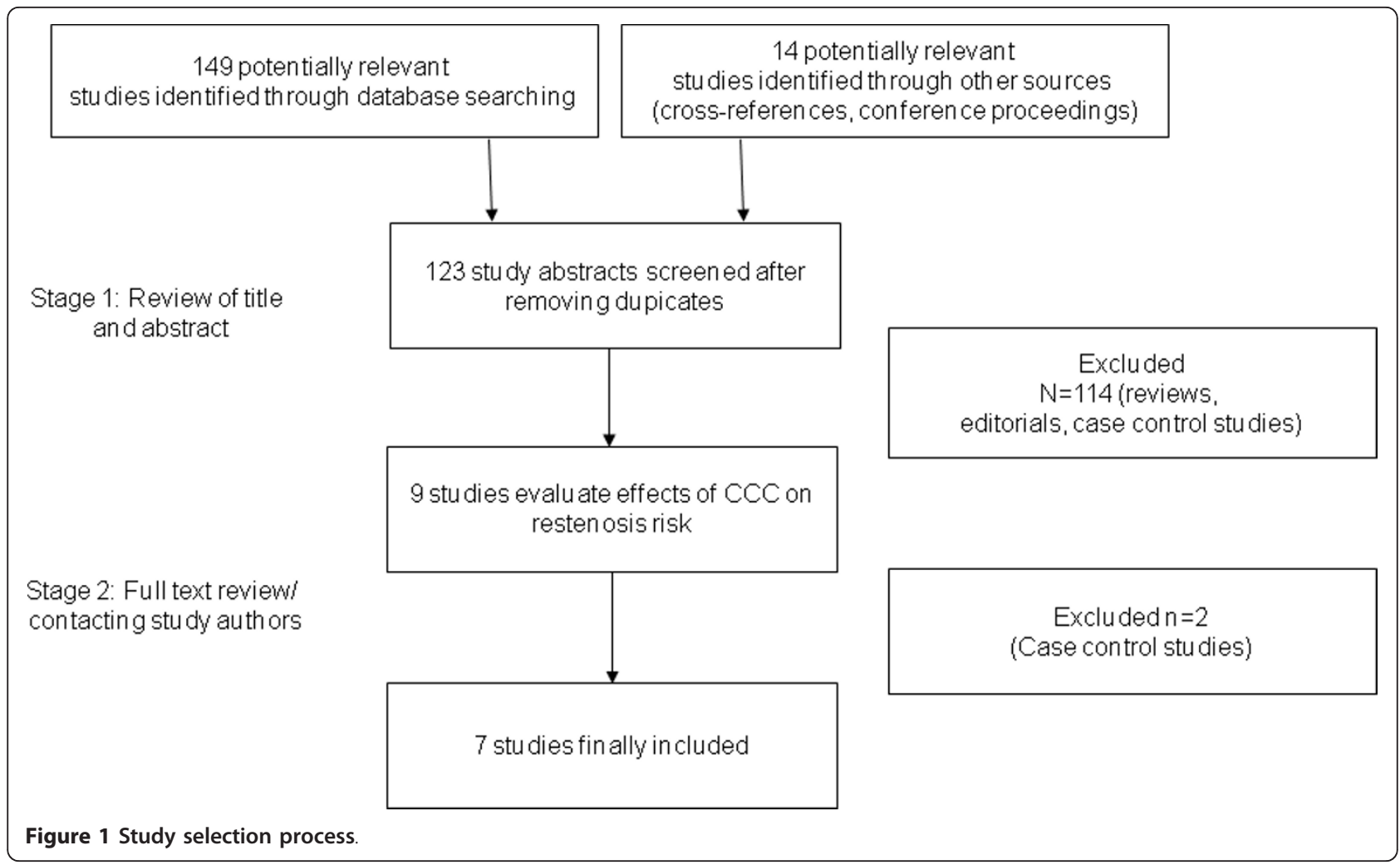

usually reported was the estimated average effect across studies [14]. Continuity correction was used when no event occurred in one group to allow calculation of a RR [15]. Heterogeneity among trials was quantified with the Higgins and Thompson $\mathrm{I}^{2}[16]$. $\mathrm{I}^{2}$ can be interpreted as the percentage of variability due to heterogeneity between studies rather than sampling error. An $\mathrm{I}^{2}>50 \%$ was considerate as an at least moderate heterogeneity. We present as our primary results estimates of the average effect across studies with 95\% confidence intervals in brackets. In addition, we also calculated $95 \%$ prediction intervals as described by Higgins et al. [14]. These intervals predict the effect that we would potentially expect to see in a new study. These data are presented in the Sensitivity analysis section. To assess the effect of moderator variables (study setting, method of collateral assessment, proportion of stent use, risk of restenosis in the control groups), a mixed-effects model was used (meta-regression). For binary moderator variables, we also present the ratio of risk ratios, which was calculated with the exponential function exp (estimated regression coefficient), with the according 95\% confidence intervals. Prespecified subgroup analyses were 'setting' (elective PCI versus acute myocardial infarction (MI)) and 'collateral assessment method' (visual versus CFI). The remainder of the subgroup/meta-regression analyses were performed post hoc in an exploratory fashion.

To assess the effect of individual studies on the summary estimate of effect, we performed an influence analysis using a jackknife procedure; pooled estimates were recalculated by omitting one study at a time. We assessed publication bias visually (funnel plot) and by

Table 1 Quality assessment of studies according to the Newcastle-Ottawa Scale

\begin{tabular}{|c|c|c|c|c|c|c|c|}
\hline $\begin{array}{l}\text { Lead } \\
\text { author }\end{array}$ & Representativeness & $\begin{array}{l}\text { Control } \\
\text { group }\end{array}$ & Ascertainment & $\begin{array}{l}\text { Endpoint not present } \\
\text { at start }\end{array}$ & $\begin{array}{l}\text { Assessment of } \\
\text { outcome }\end{array}$ & $\begin{array}{l}\text { Follow-up } \\
\text { duration }\end{array}$ & $\begin{array}{l}\text { Adequacy } \\
\text { follow-up }\end{array}$ \\
\hline Probst & $*$ & * & & $*$ & & * & $*$ \\
\hline Nakae & $*$ & * & & $*$ & & * & * \\
\hline Wahl & $*$ & * & * & $*$ & $*$ & * & \\
\hline Perera & * & * & * & * & * & * & $*$ \\
\hline Jensen & $*$ & $*$ & * & $*$ & $*$ & * & * \\
\hline Lee & * & $*$ & * & * & $*$ & * & * \\
\hline Antoniucci & * & * & & * & & * & * \\
\hline
\end{tabular}


Table 2 Summary of the characteristics of the included studies

\begin{tabular}{llllllll}
\hline Lead author & Year & CCC assessment & Setting & Follow-up (months) & PCI type & Male (\%) & Age (years) \\
\hline Probst & 1991 & Visually & Elective & 4 to 7 & POBA 100\% & 79 & 51 \\
Nakae & 1996 & Visually & Acute Ml & Mean 5.7 & POBA 100\% & 75 & 62 \\
Wahl & 2000 & CFI & Elective & Mean 17 & BMS 43\% & 74 & 60.5 \\
Lee & 2002 & CFI & Acute MI & 6 & BMS 74.3\% & 73 & 57 \\
Antoniucci & 2002 & Visually & Acute MI & 6 & BMS 64\% & 78 & 64 \\
Perera & 2006 & CFI & Elective & 6 & BMS 100\% & 80 & 60 \\
Jensen & 2007 & CFI & Elective & 9 & BMS 100\% & 75 & 61 \\
\hline
\end{tabular}

BMS, bare metal stents; CCC, coronary collateral circulation; CFI, collateral flow index (intracoronary wedge-pressure derived collateral assessment); PCI, percutaneous coronary intervention; POBA, plain balloon angioplasty; Visually, collateral assessment with Rentrop scoring system.

formal tests (rank order correlation test and Egger's test of intercept) $[17,18]$. All analyses were performed with $\mathrm{R}$ version 2.10.1 (package 'meta') [19].

\section{Results}

\section{Description of included studies}

A total of 123 articles were reviewed and 7 studies including 1,425 patients satisfied the predetermined inclusion criteria (Figure 1) [5,6,20-24]. The study of Wahl et al. has been published as a retrospective casecontrol study [25]. The study focused on patients with restenosis (case) and compared them to control patients without restenosis. The data used in this meta-analysis are based on a reanalysis of the identical cohort but with dividing patients into a group with 'good collateralization' and 'poor collateralization', depending on their CFI ( $<$ threshold versus $\geq 0.25$ ), the incidence of restenosis ( $\geq 50 \%$ diameter stenosis) was calculated for the two groups (unpublished results). Table 2 summarizes the characteristics of the included studies. All patients had routine angiographic follow-up.

\section{Restenosis risk}

Patients with a good collateralization showed a significantly increased risk for restenosis compared to patients with poor collateralization (RR 1.40 (95\% CI 1.09 to 1.80 ); $P=0.009$ (heterogeneity: $\operatorname{tau}^{2}=0.055 ; \mathrm{I}^{2}=52.2 \%$ (95\% CI 0\% to 79.7\%); $P=0.051$ ) (Figure 2).

\section{Investigation of heterogeneity}

Analyses stratified by the method of collateral assessment showed very consistent results: good collaterals were associated with an increased restenosis risk. For visually assessed collateral assessment (based on Rentrop scoring) the RR was 1.41 ((95\% CI 1.00 to 1.99$) ; P=$ 0.049 (heterogeneity: $\operatorname{tau}^{2}=0.059 ; \mathrm{I}^{2}=64.1 \%, P=$ $0.062)$ ) and for CFI-based collateral assessment, the corresponding RR was 1.37 ((95\% CI 1.03 to 1.83$) ; P=$ 0.038 (heterogeneity: $\operatorname{tau}^{2}=0.112 ; \mathrm{I}^{2}=56.1 \%, P=$ $0.077)$ ) (Figure 3). There was no significant impact of the assessment method on the risk ratio in the according meta-regression analysis, the ratio of risk ratio between 'visual assessment' and 'CFI based assessment' was 1.02 (95\% CI 0.59 to 1.71 ), $P=0.953$.

The results were also very consistent between the two studies using plain balloon angioplasty (POBA) in all patients and those two studies using bare metal stents (BMS) (Table 2). The proportion of BMS used in the individual studies had no significant effect on the result neither (meta-regression: slope -0.15 (95\% CI -10.83 to $0.54) ; P=0.221$; the meta-regression slope describes the impact of the proportion of BMS use on the study effect size; the log RR decreases on average by -0.15 when all the patients have a BMS implanted compared to the situation where none of the patients receives a BMS. (Additional file 3) Further, no significant effect of the restenosis risk in the control group (patients with poor collaterals) on the results was found neither (metaregression: slope -2.44 (95\% CI -6.54 to 1.66$) P=0.425$ ); this means that the log RR decreases on average by -2.44 if the restenosis risk in the control group (poor collaterals) is $100 \%$ compared to the situation where the restenosis risk is $0 \%$ (Additional file 4).

However, patients undergoing elective PCI for stable coronary artery disease (CAD) tended to show a more pronounced influence of collaterals on the restenosis risk. The risk ratio for those with good collateralization was 1.64 (95\% CI 1.14 to 2.35 ); $P=0.008$ (heterogeneity: $\left.\left.\operatorname{tau}^{2}=0.049 ; \mathrm{I}^{2}=35.9 \%, P=0.197\right)\right)$. For patients with acute myocardial infarction, however, the respective RR was 1.23 (95\% CI 0.89 to 1.69 ); $P=0.212$ (heterogeneity: $\left.\operatorname{tau}^{2}=0.049 ; \mathrm{I}^{2}=58.3 \%, P=0.091\right)$ ) (Figure 4). However, the according meta-regression analysis showed no statistically significant effect of this variable on the RR, the ratio of risk ratio between 'elective PCI' and 'acute MI' was 1.33 (95\% CI 0.82 to 2.16 ), $P=0.243$.

\section{Sensitivity analyses}

None of the studies influenced the results to the extent that the conclusion would have changed; the jackknife procedure-based sensitivity analysis omitting one study at a time consistently showed that good collateralization 


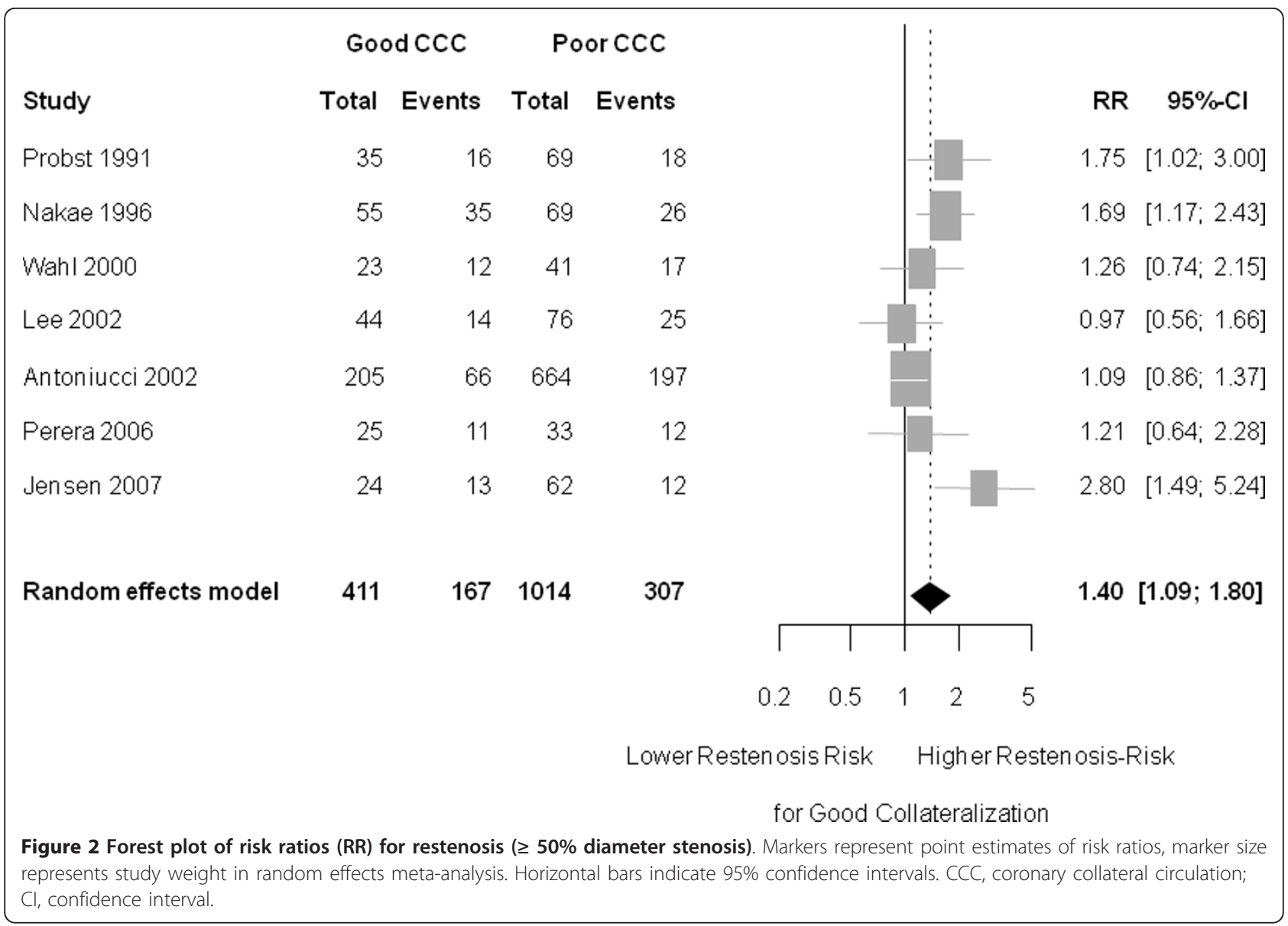

is associated with an increased restenosis risk (Figure 5). Specifically, excluding the only unpublished data included in this analysis (based on Wahl et al. [25]) did not change the overall RR estimate (RR 1.43 (95\% CI 1.07 to 1.91 ); $P=0.016$ (heterogeneity: $\operatorname{tau}^{2}=0.074 ; \mathrm{I}^{2}$ $=60.1 \%, P=0.028)$ ). When considering studies with highest quality only (based on the Newcastle-Ottawa Scale; at least seven of eight points), the estimate for RR for restenosis for the group with good collaterals was very consistent but did not reach statistical significance (1.47 (95\% CI 0.78 to 2.76 ); $P=0.235$ (heterogeneity: tau $\left.\left.^{2}<0.001 ; \mathrm{I}^{2}=0 \%, P=0.866\right)\right)$; three studies were considered in this analysis $[5,6,24]$.

The funnel plot was symmetrical (Figure 6) and formal testing did not indicate a relevant 'small study effect' or publication bias (Egger's test $P=0.362$, rank correlation test $P=0.273$ ).

Three studies enrolled patients with acute MI. While the visual assessment of collaterals should not be altered and may even be more accurate, because the vessel of interest is occluded and avoids 'competitive' flow via the native and the collateral vessels, the accuracy of quantitative CFI measurements have been questioned in this setting [26]. When excluding the one study using CFI measurements in acute MI [6], the overall result increases minimally, from RR 1.40 (95\% CI 1.09 to 1.80 ) to RR 1.48 (95\% CI 1.12 to 1.94 ); $P=0.005$ (heterogeneity: $\left.\operatorname{tau}^{2}=0.061 ; \mathrm{I}^{2}=55.5 \%, P=0.047\right)$. For the subgroup of acute MI patients, the RR increases from 1.23 (95\% CI 0.89 to 1.69 ) to RR 1.32 ( $95 \%$ CI 0.86 to 2.04 ); $P=0.204$ (heterogeneity: $\operatorname{tau}^{2}=0.075 ; \mathrm{I}^{2}=75.7 \%, P=0.043$ ).

Lastly, we also calculated prediction intervals, which are wider compared to confidence intervals. For the overall results, including all studies, the RR was 1.40 with a prediction interval of 0.70 to 2.78 . For the patients with elective PCI, it was 1.64 (0.47 to 5.65$)$, for those with acute MI it was 1.23 (0.04 to 38.11).

This means that we predict that the true effect in a new study (assumed to be 'similar' to those studies included in the meta-analysis) would lie between RR = 0.70 and $R R=2.78$ with $95 \%$ confidence. As such, although the average effect across studies of a $40 \%$ increase in restenosis in patients with a good collateralization is statistically significant, due to unexplained heterogeneity between existing results we cannot be sure of an effect in a new study. 


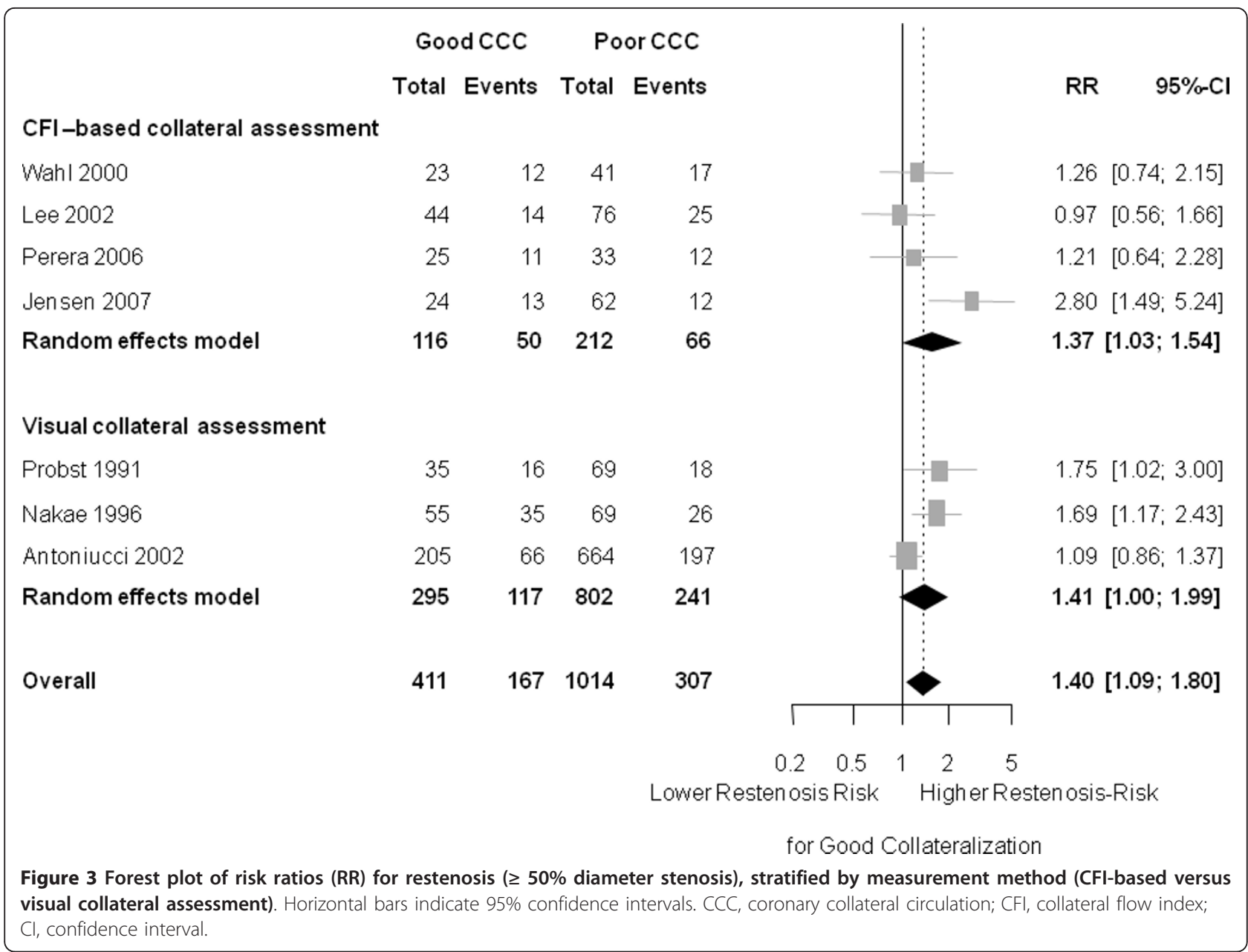

\section{Discussion}

This meta-analysis of seven studies shows that a 'good collateralization' is predictive for restenosis in patients undergoing PCI. This risk was found to be increased by $40 \%$ (95\% CI $0 \%$ to $80 \%$ ) compared to patients with poor collateralization. This association was found to be stronger in patients with stable coronary artery disease (risk increased by $64 \%(14 \%$ to $135 \%)$ ) while it was weaker for patients with acute MI (risk increased by $23 \%(-11 \%$ to $69 \%))$ and did not reach statistical significance in this subset. It has to be considered that the differences of the RR estimates between these subgroup analyses were not statistically significant. Moreover, all these values are estimates of the average effect across the different studies.

This data indicate that the degree of collateralization may be a useful and simple tool to inform individual clinical decision making, patients at high risk for restenosis may profit from the more expensive drug-eluting stents and from cilostazol, which both reduce the restenosis risk $[27,28]$.

\section{Collaterals: good or bad?}

Good coronary collateralization has been found to be associated with improved survival $[3,4,29]$. In this regard it may seem contradictory that good collateralization is a risk factor for restenosis after PCI. Similarly, accelerated disease progression of the native vessel after coronary artery bypass grafting $(\mathrm{CABG})$ is a frequent phenomenon that does not affect the clinical benefit of CABG [30].

Coronary collaterals may be regarded as an analog to CABG in that both provide an alternative blood supply to the myocardium. Therefore, increased restenosis after PCI and improved survival benefit in patients with good collateralization are not mutually exclusive. Restenosis is usually a slow process and rarely results in a life-threatening event. This is demonstrated by the fact that most treatments that reduce the risk for restenosis, for example, drug eluting stents, do not result in improved survival.

\section{Potential mechanisms}

One of the possible reasons for the increased risk of restenosis in case of a good collateralization is the flow 


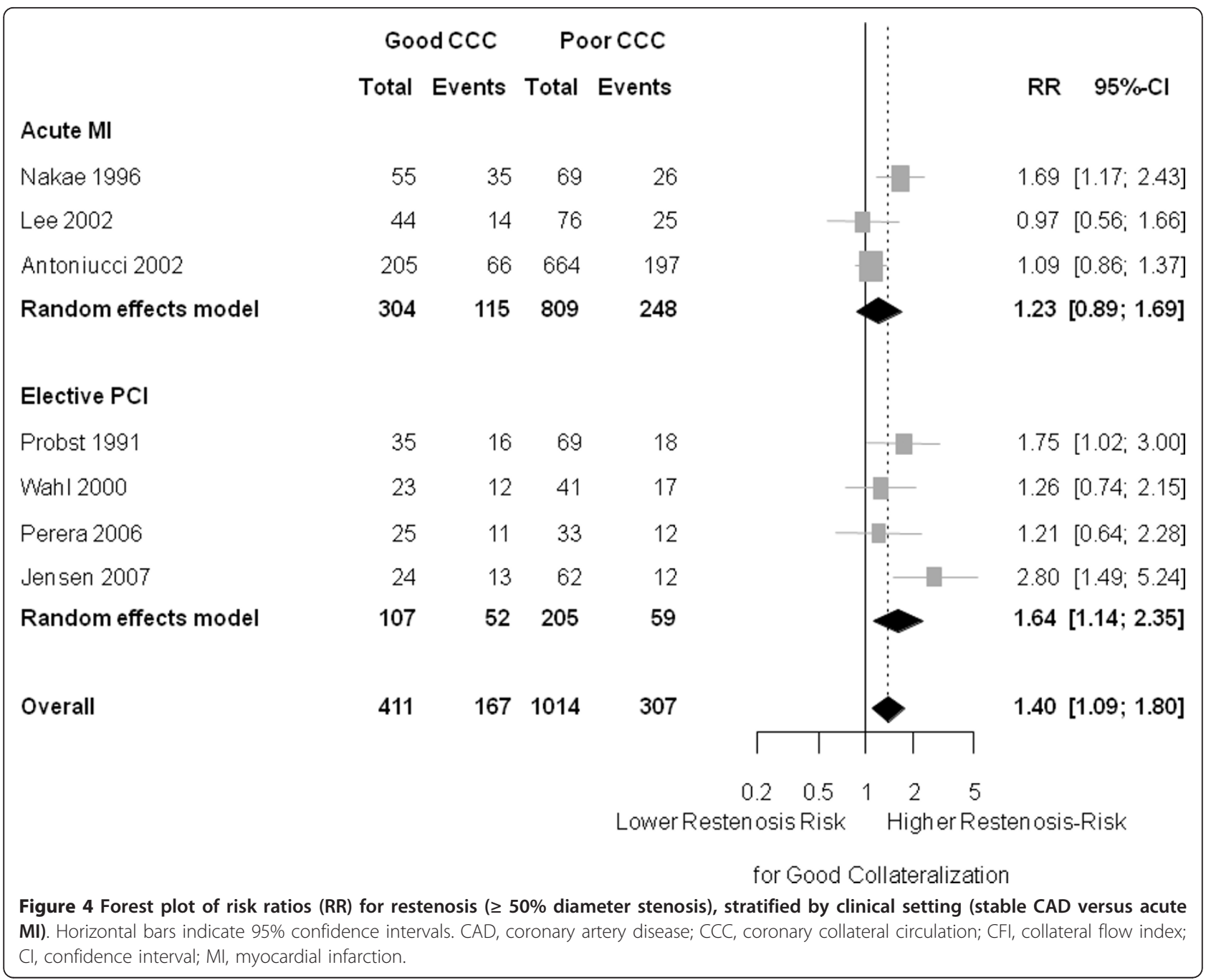

via the collaterals, which competes with the antegrade blood flow through the native vessel $[23,31,32]$. As mentioned above, a similar phenomenon is frequently observed in native coronary arteries in proximity to a bypass graft, which also represents a collateral circulation, leading to decreased flow through the native vessel $[31,32]$. This reduced flow subsequently results in a decreased shear stress on the endothelial cell layer. This shear stress is known to be atheroprotective [33]. Monocytes and platelets are key players in the pathogenesis of intimal hyperplasia and atherosclerosis; low flow and low shear stress increases the chance of cell adhesion to the vessel walls [34]. Low shear stress also modulates endothelial cell gene expression into a proinflammatory state [35]. High shear stress, on the other hand, is suppressing the expression of these proinflammatory genes, specifically via the lung Kruppel-like factor (LKLF), an anti-inflammatory endothelial transcription factor $[36,37]$. LKLF also reduces the expression of the substance monocyte chemoattractant protein 1 (MCP$1)$. As its name suggests, MCP-1 attracts monocytes and has a proatherogenic effect [38]. However, the exact mechanism of this 'mechanotransduction', translating physical forces into changes at a molecular level, is not completely understood. Data suggest that $G$ proteins may act as primary mechanosensors on endothelial cells; a further concept that has evolved are mechanosensitive ion channels that translate the physical force into a corresponding intracellular signal [39].

\section{Coronary collaterals as a marker or as a causal risk factor for restenosis?}

The major determinant of collateral function is the degree of vessel stenosis, which itself has been described to increase restenosis risk [40-42]. The studies included in this meta-analysis did not adjust for covariates such as vessel diameter stenosis or the extent of CAD. As an alternative explanation, coronary collaterals could simply 


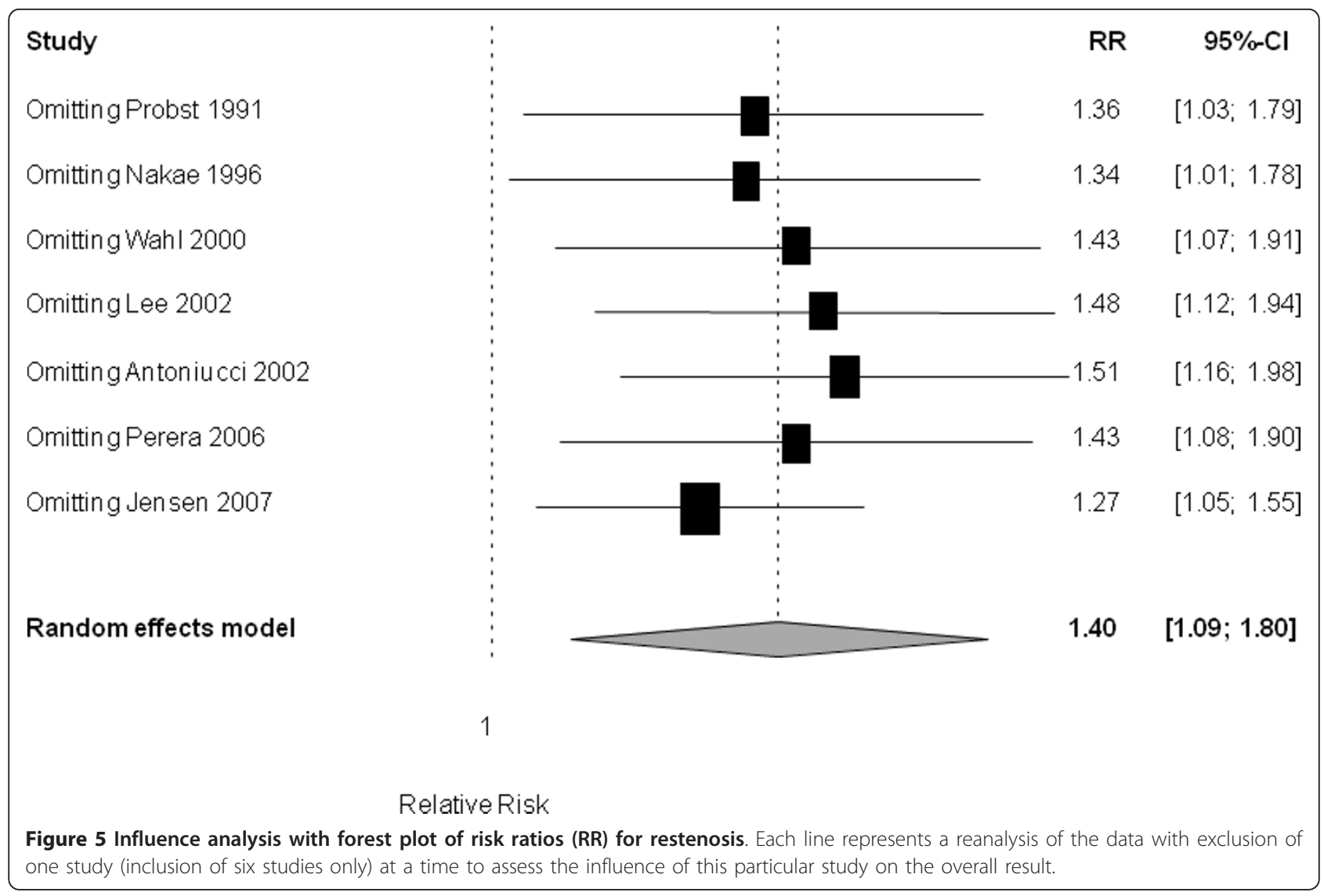

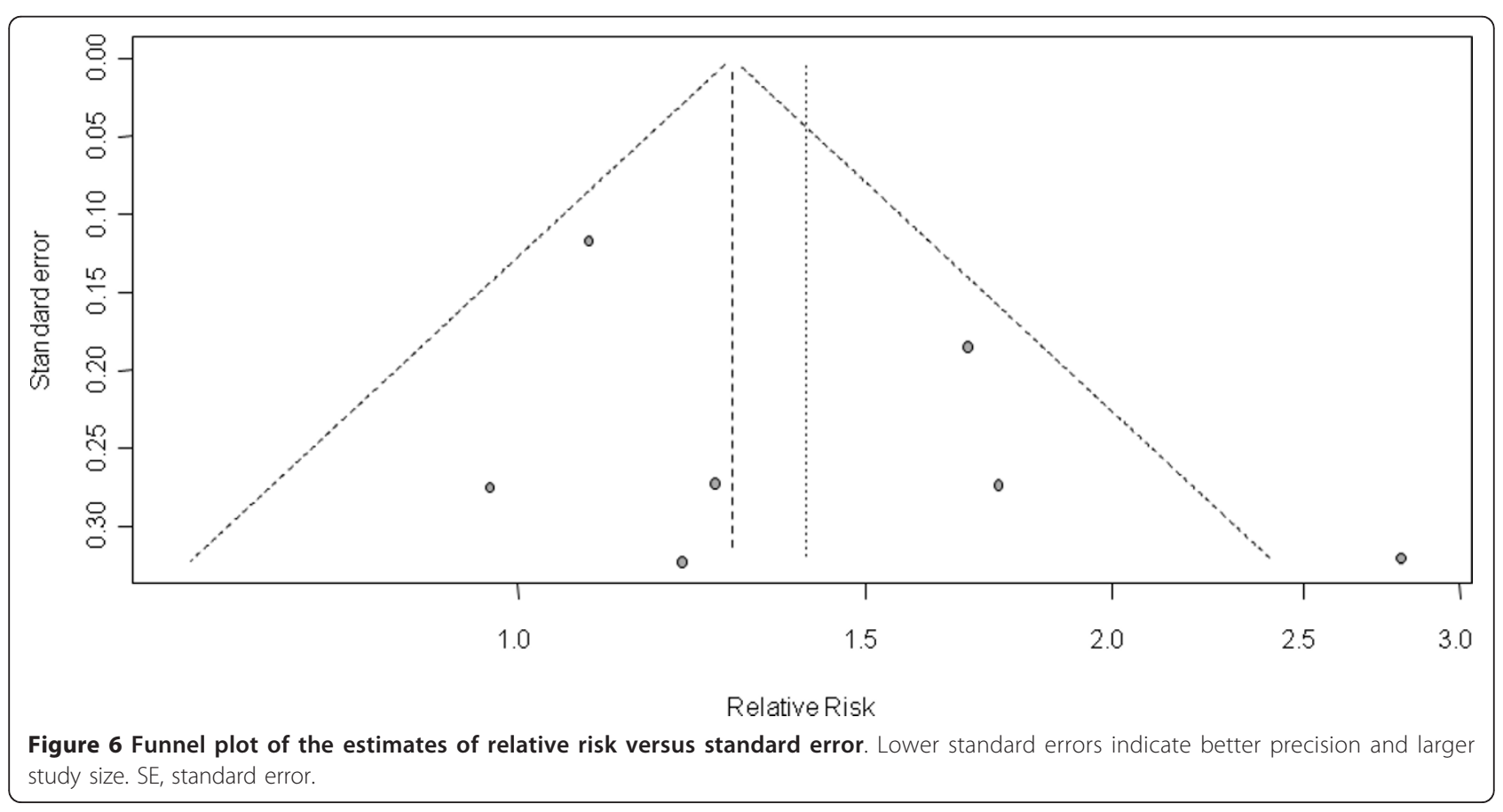


represent markers for more severe underlying CAD with consecutive increased risk for restenosis after PCI. This interesting question remains to be resolved in future studies. Regardless of a causal or a casual association, the degree of coronary collateralization represents a valuable and simple marker to predict the risk for restenosis.

\section{Outlook}

Future research should evaluate possible mechanisms of this increased restenosis risk in patients with good collateralization. This patient group may show different levels of cytokine activation, inflammation, levels of reactive oxygen species (ROS) or platelet activation after percutaneous transluminal coronary angioplasty (PTCA), which may be addressed by additional pharmacologic approaches. One hypothesis to be tested is that the oxygen level distal to the vessel occlusion during angioplasty varies with varying collateralization and may lead to different ROS levels. Higher ROS levels may damage endothelial cells downstream and thereby increase the risk for restenosis.

\section{Limitations of this meta-analysis}

Most studies used exclusively binary data for their analysis. The extent of variable of interest, collateralization, was dichotomized into 'good collateralization' and 'poor collateralization', while in fact the degree of collateralization is a continuous variable. Besides this variable of interest, the outcome was also dichotomized in most studies, using a restenosis threshold of $50 \%$. One drawback of this approach is the impaired statistical power. Still, this meta-analysis was large enough to detect a significant influence of collaterals on restenosis risk. A related problem is the fact that all patients underwent routine angiographic follow-up. Some of the patients may have had a stable in-stent restenosis without symptoms, the routine angiographic follow-up may overrate the clinical importance of restenosis and it may overestimate the impact of collaterals on restenosis [43].

Further, the included studies did not adjust for potential confounding factors such as the severity of CAD, the diameter stenosis, and so on. Since this is a studylevel and not a patient-level meta-analysis, we were not able to include these factors in our analyses. However, we think that significant confounding regarding our primary outcomes is rather unlikely. The main determinant of collaterals (our predictor) is the degree of the vessel diameter stenosis; the narrower the stenosis, the better the collaterals [40]. However, the degree of stenosis is not known to be a risk factor for future restenosis (primary outcome of our study).

Moreover, this study does not capture the dynamic of the coronary collaterals. The coronary collateral function has been demonstrated to decrease over a 6month period after PCI [44]. This dynamic may explain the non-significant results in the setting of acute MI. During an acute vessel occlusion, the collaterals undergo rapid changes; a fact, that limits the value of a single timepoint measurement. Further, the increased left ventricular end diastolic pressure during acute MI impairs the accuracy of the collateral assessment [26].

Another important limitation is the heterogeneity among the studies included in this analysis. The extent of heterogeneity reduces the robustness of our results. We therefore performed several subset analyses and meta-regression analysis, and found several aspects that contribute to this heterogeneity. The most important one is the difference in study populations. Four studies included patients with stable CAD while three studies focused on patients with acute MI (Table 2). Further, the earliest two studies used plain balloon angioplasty while the newest studies used bare metal stents in all patients [5,24]. Also, four studies used CFI-based collateral assessment while three studies used visual assessment of collaterals. Despite this heterogeneity between studies, the findings were very consistent in most of the subset and sensitivity analyses. Moreover, the accuracy of CFI measurements in the setting of acute MI has been questioned [26]. However, this only applies to one study [6] and excluding this study only minimally influenced the overall results (see 'Sensitivity analyses').

A further drawback of this study is that early studies used plain balloon angioplasty and later studies used BMS. No drug-eluting stents (DES) were used in the present studies. Whether the results of this meta-analysis can be generalized to DES remains unanswered. DES have further reduced the risk for restenosis; it is highest for POBA (32\% in average), around 22\% for BMS and around $16 \%$ for first-generation DES $[45,46]$. The predictive value of collaterals may be reduced in the context of DES. However, even with DES, restenosis is still a significant and unresolved problem. Our findings were consistent in the POBA and in the BMS group; they were not significantly influenced by the proportion of BMS use in the individual studies or by the average restenosis risk in the control groups (poor collaterals). We would therefore expect similar results for drug-eluting stents.

Another limitation of our study is that it does not provide further insights into possible causal mechanisms of our findings. Our considerations in the Discussion are thus rather hypothetical. This study, overall, is hypothesis generating rather than confirmatory.

With regard to the meta-regression analyses, it has to be considered that they have limited statistical power and a lack of statistical significance does not necessarily mean that there is no true effect. 


\section{Conclusions}

The results of this meta-analysis including 1,425 patients show that a good coronary collateralization indicates an increased risk for restenosis. The degree of coronary collateralization may be useful information for clinical decision making during PCI, such as stent choice (DES versus BMS) and use of cilostazol, and it may also impact the aggressiveness of the post-PCI management.

\section{Author information}

PM is an interventional Cardiologist at UCLH, London and is leading the Yale-UCL Device Development Program. He has a degree in applied statistics and has several years of experience in clinical research on the coronary collateral circulation and on meta-analyses (for more information, see http://www.drpascalmeier.com). BP is a Cardiologist and Professor at the University of Michigan. He was among the first researchers to demonstrate the existence of collateral circulation in the heart, published in 1959. GK is an Associate Professor for Statistics at TU University, Dortmund. He has developed meta-analysis methods, such as the HartungKnapp method, which is implemented in advanced statistics software and has coauthored a book on statistical aspects of meta-analyses. AJL is a cardiologist and an Associate Professor at Yale University and an expert in PCI research and restenosis; she has had a leading role in many of the landmark trials in this field. CS is an interventional cardiologist and Professor at University Hospital Bern, and has long-standing experience in clinical research on coronary collateral circulation.

\section{Additional material}

Additional file 1: MOOSE Checklist. The MOOSE (Meta-analysis Of Observational Studies in Epidemiology) checklist is recommended to report on meta-analyses of observational studies and aims to ensure sufficient information about background, search strategy, methods, results, discussion, and conclusion.

Additional file 2: Search strategy. Detailed description of search strategy and search terms used for the systematic review.

Additional file 3: Meta-regression of stent effect. Meta-regression analysis of the proportion of bare-metal stents used versus the relative risk estimates.

Additional file 4: Meta-regression of restenosis risk effect. Metaregression analysis of the restenosis risk in the control group (poor collaterals) versus the relative risk estimates.

\section{Acknowledgements}

This study was supported by the Swiss National Science Foundation SNF (grant number 3200BO-112341 to CS).

\section{Author details}

${ }^{1}$ The Heart Hospital London, University College London Hospital Trust, London, UK. 'St Thomas' Hospital, Department of Cardiology, King's College London, UK. ${ }^{3}$ University of Michigan Medical Center, Department of
Cardiology, Ann Arbor, MI, USA. ${ }^{4}$ University Hospital Bern, Department of Cardiology, Bern, Switzerland. ${ }^{5}$ University of Oslo, Department of Cardiology, Oslo, Norway. ${ }^{6}$ TU University Dortmund, Department of Statistics, Dortmund, Germany. ${ }^{7}$ Yale University Medical Center, Department of Cardiology, New Haven, CT, USA.

\section{Authors' contributions}

PM was responsible for the conception and design, acquisition of data, analysis and interpretation of data, drafting the initial manuscript and revising it critically for important intellectual content. Al was responsible for acquisition of data, data control, interpretation of data and for revising the manuscript critically for important intellectual content. TT, SFdM, TK, and AJL were responsible for revising the manuscript critically for important intellectual content. GK was responsible for analysis and interpretation of data and for revising the manuscript critically for important intellectual content. CS was responsible for the conception and design, acquisition of data, interpretation of data, and for revising the manuscript critically for important intellectual content. All authors read and approved the final manuscript.

\section{Competing interests}

BP received consultant fees from Pfizer, Novartis, Merck, Takeda, BoehringerIngelheim, Bayer, Forrest Laboratories, GE Health Care, Relypsa, Nile

Therapeutics, Aurasense and has stock options of Relypsa, Nile Therapeutics, Aurasense. BP received research grants from Medtronic, Novartis and Bayer.

The other authors have no conflicts of interest to disclose.

Received: 17 August 2011 Accepted: 21 June 2012

Published: 21 June 2012

\section{References}

1. Seiler C: The human coronary collateral circulation. Eur J Clin Invest 40:465-476.

2. Pitt B: Interarterial coronary anastomoses. Occurrence in normal hearts and in certain pathologic conditions. Circulation 1959, 20:816-822.

3. Meier P, Gloekler S, Zbinden R, Beckh S, de Marchi SF, Zbinden S, Wustmann K, Billinger M, Vogel R, Cook S, Wenaweser P, Togni M, Windecker S, Meier B, Seiler C: Beneficial effect of recruitable collaterals: a 10-year follow-up study in patients with stable coronary artery disease undergoing quantitative collateral measurements. Circulation 2007, 116:975-983.

4. Meier P, Hemingway H, Lansky AJ, Knapp G, Pitt B, Seiler C: The impact of the coronary collateral circulation on mortality: a meta-analysis. Eur Heart J 2012, 33:614-621.

5. Jensen LO, Thayssen P, Lassen JF, Hansen HS, Kelbaek H, Junker A, Pedersen KE, Hansen KN, Krusell LR, Botker HE, Thuesen L: Recruitable collateral blood flow index predicts coronary instent restenosis after percutaneous coronary intervention. Eur Heart J 2007, 28:1820-1826.

6. Lee CW, Hong MK, Choi SW, Kim JH, Kim JJ, Park SW, Park SJ: Influence of coronary collateral flow on restenosis following primary angioplasty for acute myocardial infarction. Catheter Cardiovasc Interv 2002, 55:477-481.

7. Stroup DF, Berlin JA, Morton SC, Olkin I, Williamson GD, Rennie D, Moher D, Becker BJ, Sipe TA, Thacker SB: Meta-analysis of observational studies in epidemiology: a proposal for reporting. Meta-analysis Of Observational Studies in Epidemiology (MOOSE) group. JAMA 2000, 283:2008-2012.

8. Wells GA, Brodsky LO, O'Connell D, Shea B, Henry D, Mayank S, Tugwell P: An evaluation of the Newcastle Ottawa scale: an assessment tool for evaluating the quality of non-randomized studies (abstract). XI International Cochrane Colloquium Book of Abstracts, 0-63 Presented at the XI Cochrane Colloquium, Barcelona; 2003, 26.

9. Juni P, Witschi A, Bloch R, Egger M: The hazards of scoring the quality of clinical trials for meta-analysis. JAMA 1999, 282:1054-1060

10. Gould KL, Lipscomb K, Hamilton GW: Physiologic basis for assessing critical coronary stenosis. Instantaneous flow response and regional distribution during coronary hyperemia as measures of coronary flow reserve. Am J Cardiol 1974, 33:87-94.

11. Rentrop KP, Cohen M, Blanke H, Phillips RA: Changes in collateral channel filling immediately after controlled coronary artery occlusion by an angioplasty balloon in human subjects. J Am Coll Cardiol 1985, 5:587-592.

12. Seiler C, Fleisch M, Garachemani A, Meier B: Coronary collateral quantitation in patients with coronary artery disease using intravascular 
flow velocity or pressure measurements. J Am Coll Cardiol 1998, 32:1272-1279.

13. DerSimonian R, Laird N: Meta-analysis in clinical trials. Control Clin Trials 1986, 7:177-188.

14. Higgins JP, Thompson SG, Spiegelhalter DJ: A re-evaluation of randomeffects meta-analysis. J R Stat Soc Ser A Stat Soc 2009, 172:137-159.

15. Sankey $S$, Weissfeld L, Fine M, Kapoor W: An assesment of the use of of the continuity correction for sparse data in metanalysis. Commun Stat BSimul 1996, 25:1031-1056.

16. Higgins JP, Thompson SG: Quantifying heterogeneity in a meta-analysis. Stat Med 2002, 21:1539-1558

17. Begg C, Mazumdar M: Operating characteristics of a rank correlation test for publication bias. Biometrics 1994, 50:1088-1101.

18. Egger M, Davey Smith G, Schneider M, Minder C: Bias in meta-analysis detected by a simple, graphical test. BMJ 1997, 315:629-634.

19. R Development Core Team: R: A language and environment for statistical computing.[http://www.R-project.org].

20. Antoniucci D, Valenti R, Moschi G, Migliorini A, Trapani M, Santoro GM, Bolognese L, Cerisano G, Buonamici P, Dovellini EV: Relation between preintervention angiographic evidence of coronary collateral circulation and clinical and angiographic outcomes after primary angioplasty or stenting for acute myocardial infarction. Am J Cardiol 2002, 89:121-125.

21. Probst $P$, Baumgartner $C$, Gottsauner-Wolf $M$ : The influence of the presence of collaterals on restenoses after PTCA. Clin Cardiol 1991, 14:803-807.

22. Nakae I, Fujita M, Fudo T, Iwase T, Tanaka T, Tamaki S, Nohara R, Sasayama S: Relation between preexistent coronary collateral circulation and the incidence of restenosis after successful primary coronary angioplasty for acute myocardial infarction. J Am Coll Cardiol 1996, 27:1688-1692.

23. Wahl A, Billinger M, Fleisch M, Meier B, Seiler C: Quantitatively assessed coronary collaterals and restenosis following percutaneous revascularization. Eur Heart J 1998, 19(Suppl):389.

24. Perera D, Postema P, Rashid R, Patel S, Blows L, Marber M, Redwood S: Does a well developed collateral circulation predispose to restenosis after percutaneous coronary intervention? An intravascular ultrasound study. Heart 2006, 92:763-767.

25. Wahl A, Billinger M, Fleisch M, Meier B, Seiler C: Quantitatively assessed coronary collateral circulation and restenosis following percutaneous revascularization. Eur Heart J 2000, 21:1776-1784.

26. de Marchi SF, Oswald P, Windecker S, Meier B, Seiler C: Reciprocal relationship between left ventricular filling pressure and the recruitable human coronary collateral circulation. Eur Heart J 2005, 26:558-566.

27. Tamhane U, Meier P, Chetcuti S, Chen KY, Rha SW, Grossman MP, Gurm H: Efficacy of cilostazol in reducing restenosis in patients undergoing contemporary stent based PCl: a meta-analysis of randomised controlled trials. Eurolntervention 2009, 5:384-393.

28. Stettler C, Allemann S, Wandel S, Kastrati A, Morice MC, Schömig A, Pfisterer ME, Stone GW, Leon MB, de Lezo JS, Goy JJ, Park SJ, Sabaté M, Suttorp MJ, Kelbaek H, Spaulding C, Menichelli M, Vermeersch P, Dirksen MT, Cervinka P, De Carlo M, Erglis A, Chechi T, Ortolani P, Schalij MJ, Diem $P$, Meier $B$, Windecker $S$, Jüni $P$ : Drug eluting and bare metal stents in people with and without diabetes: collaborative network metaanalysis. BMJ 2008, 337:a1331.

29. Meier P, Gloekler S, de Marchi SF, Zbinden R, Delacretaz E, Seiler C: An indicator of sudden cardiac death during brief coronary occlusion: electrocardiogram QT time and the role of collaterals. Eur Heart J 2010, 31:1197-1204

30. Hlatky MA, Boothroyd DB, Bravata DM, Boersma E, Booth J, Brooks MM, Carrié D, Clayton TC, Danchin N, Flather M, Hamm CW, Hueb WA, Kähler J, Kelsey SF, King SB, Kosinski AS, Lopes N, McDonald KM, Rodriguez A, Serruys P, Sigwart U, Stables RH, Owens DK, Pocock SJ: Coronary artery bypass surgery compared with percutaneous coronary interventions for multivessel disease: a collaborative analysis of individual patient data from ten randomised trials. Lancet 2009, 373:1190-1197.

31. Aldridge HE, Trimble AS: Progression of proximal coronary artery lesions to total occlusion after aorta-coronary saphenous vein bypass grafting. J Thorac Cardiovasc Surg 1971, 62:7-11.

32. Cashin WL, Sanmarco ME, Nessim SA, Blankenhorn DH: Accelerated progression of atherosclerosis in coronary vessels with minimal lesions that are bypassed. N Engl J Med 1984, 311:824-828.
33. Stone PH, Coskun AU, Kinlay S, Clark ME, Sonka M, Wahle A, llegbusi OJ, Yeghiazarians Y, Popma JJ, Orav J, Kuntz RE, Feldman CL: Effect of endothelial shear stress on the progression of coronary artery disease, vascular remodeling, and in-stent restenosis in humans: in vivo 6-month follow-up study. Circulation 2003, 108:438-444.

34. Fan L, Karino T: Effect of a disturbed flow on proliferation of the cells of a hybrid vascular graft. Biorheology 47:31-38.

35. Pan S: Molecular mechanisms responsible for the atheroprotective effects of laminar shear stress. Antioxid Redox Signal 2009, 11:1669-1682.

36. Dekker RJ, van Soest S, Fontijn RD, Salamanca S, de Groot PG, VanBavel E, Pannekoek $\mathrm{H}$, Horrevoets AJ: Prolonged fluid shear stress induces a distinct set of endothelial cell genes, most specifically lung Kruppel-like factor (KLF2). Blood 2002, 100:1689-1698.

37. Parmar KM, Larman HB, Dai G, Zhang Y, Wang ET, Moorthy SN, Kratz JR, Lin Z, Jain MK, Gimbrone MA Jr, García-Cardeña G: Integration of flowdependent endothelial phenotypes by Kruppel-like factor 2. J Clin Invest 2006, 116:49-58

38. Dekker RJ, van Thienen JV, Rohlena J, de Jager SC, Elderkamp YW Seppen J, de Vries CJ, Biessen EA, van Berkel TJ, Pannekoek H, Horrevoets AJ: Endothelial KLF2 links local arterial shear stress levels to the expression of vascular tone-regulating genes. Am J Pathol 2005 , 167:609-618

39. Traub O, Berk BC: Laminar shear stress: mechanisms by which endothelial cells transduce an atheroprotective force. Arterioscler Thromb Vasc Biol 1998, 18:677-685.

40. Pohl T, Seiler C, Billinger M, Herren E, Wustmann K, Mehta H, Windecker S, Eberli FR, Meier B: Frequency distribution of collateral flow and factors influencing collateral channel development. Functional collateral channel measurement in 450 patients with coronary artery disease. J Am Coll Cardiol 2001, 38:1872-1878.

41. Schaper W: Collateral circulation: past and present. Basic Res Cardiol 2009, 104:5-21.

42. Wen S, Mao J, Guo L: Multivariate analysis of clinical factors in restenosis after coronary interventional treatment [in Chinese]. Zhonghua Yi Xue Za Zhi 1999, 79:197-199.

43. Pinto DS, Stone GW, Ellis SG, Cox DA, Hermiller J, O'Shaughnessy C, Mann JT, Mehran R, Na Y, Turco M, Caputo R, Popma JJ, Cutlip DE, Russell ME, Cohen DJ, TAXUS-IV Investigators: Impact of routine angiographic follow-up on the clinical benefits of paclitaxel-eluting stents: results from the TAXUS-IV trial. J Am Coll Cardiol 2006, 48:32-36.

44. Perera D, Kanaganayagam GS, Saha M, Rashid R, Marber MS, Redwood SR: Coronary collaterals remain recruitable after percutaneous intervention. Circulation 2007, 115:2015-2021.

45. Farooq V, Gogas BD, Serruys PW: Restenosis: delineating the numerous causes of drug-eluting stent restenosis. Circ Cardiovasc Interv 4:195-205.

46. Serruys PW, de Jaegere P, Kiemeneij F, Macaya C, Rutsch W, Heyndrickx G, Emanuelsson H, Marco J, Legrand V, Materne P, Belardi J, Sigwart U, Colombo A, Goy JJ, van den Heuvel P, Delcan J, Morel M-a, Benestent Study Group: A comparison of balloon-expandable-stent implantation with balloon angioplasty in patients with coronary artery disease. Benestent Study Group. N Engl J Med 1994, 331:489-495.

\section{Pre-publication history}

The pre-publication history for this paper can be accessed here: http://www.biomedcentral.com/1741-7015/10/62/prepub

doi:10.1186/1741-7015-10-62

Cite this article as: Meier et al: Coronary collaterals and risk for restenosis after percutaneous coronary interventions: a meta-analysis. BMC Medicine 2012 10:62. 